
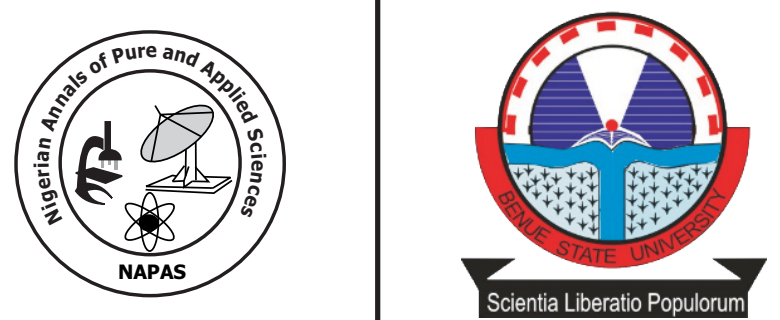

\title{
Isolation Identification and Characterization of Diterpenes from the Stem bark of Detarium Microcarpum
}

\author{
Gera, Y., ${ }^{1}$ Umeh, E.U. ${ }^{1}$,Tor-Anyiin, T.A., ${ }^{2}$ and Iheukwumere, C.C. ${ }^{1}$ \\ ${ }^{1}$ Dept. of biological sciences, University of Agriculture Makurdi, Nigeria. \\ ${ }^{2}$ Dept. of Chemistry University of Agriculture Makurdi \\ P.M.B. 2373 Makurdi, Nigeria. \\ *Corresponding author:yatorgera@gmail.com.
}

\section{Abstract}

The antibacterial activity of the stem bark of Detarium microcarpum was investigated with the aim of isolating the most active ingredient. Extraction solvents used to prepare the crude extracts of the stem bark were, n-hexane, ethyl acetate, chloroform, methanol. Test bacteria included Escherichia coli, Salmonella enteriditis, Shigella dysenteriae, Staphylococcus aureus and Vibro cholerae. The extracts demonstrated a wide range of antibacterial activity on the microorganisms, with the ethyl acetate crude extract being the most active. Using liquid vacuum chromatography over silica gel, the extract was eluted with n- hexane, ethyl acetate and methanol and fifty- five fractions labeled Gl G55 were obtained. Further antibacterial assays of the fractions led to the identification of fraction G34 as the most active fraction. This fraction was subjected to spectroscopic analysis using NMR, $\left[\left({ }^{1} \mathrm{H}-{ }^{1} \mathrm{H}\right.\right.$ NMR, $\left.{ }^{13} \mathrm{C}-\mathrm{NMR}\right)$ and 2D-NMR (COSY and HMBC) $)$. The results showed good agreement with reported data on Copalic acid, a diterpene with chemical formula $\mathrm{C}_{2} \mathrm{O} \mathrm{H}_{34} \mathrm{O}_{2}$. This compound is the most active ingredients of this plant and is likely to be responsible for its antibacterial activities. 


\section{Introduction}

Human society has had from its beginning a strong dependence on plants and its products, for their health care needs particularly, and for various other purposes.

This almost total dependence continued until the introduction of chemotherapeutic agents, powerful chemical preparations that offered almost immediate and direct cure to ailments, and also easy to carry about. With these agents the dependence on herbal medicines waned.

The challenge of multidrug resistant microbial strains with their reduced susceptibility to antibiotics has awakened interest in the search for alternative sources of drugs (Aibunu et al., 2007). Researchers are now focusing on plants as the main source of health care or a compulsory alternative (VanWhyk, 2002; and Teklehaymano, et.al. 2007). Recent study on chemical diversity of plants reveals the presence in them of powerful healing agents' the-phytochemicals.

According to WHO (2001), 80\% of people depends on plant for most of their health care need. Most of the information about the efficacy of medical plants is from the mouth of the herbalists. Information on the efficacy and the chemical diversity of the most medicinal plant based on scientific investigation is lacking. Since there is a thin line between the hyaollunogenic and toxic dosages, there is need to investigate plants not only to defend efficacy but up to the assessment of their active ingredients, which is the aim of this study.

\section{Materials and Methods.}

Plants collection: The plants were collected at the new layout near owner occupier housing unit, Makurdi and the department of Forestry and Wild life help in the identification.

\section{Preparation of Crude Extracts}

Stem bark of Detarium microcarpum were dried under shade and ground into fine powder using sterilized laboratory mortars. N-hexane $(500 \mathrm{~mL})$ was added to $100 \mathrm{~g}$ of the powdered sample in a1000 mL conical flask. The mixture was stirred and allowed to stand for $72 \mathrm{~h}$, and then filtered using Whatman filter paper No. 2. The filtrates were kept in sterilized containers and the residue was dried under shade. The same procedure was repeated sequentially using ethyl acetate, chloroform, and methanol in that order. At each point of extraction the sample was dried before another solvent was introduced. The extracts were then concentrated using rotary evaporator at $50{ }^{\circ} \mathrm{C}$. All the extracts were cooled and stored in the refrigerator at $2{ }^{\circ} \mathrm{C}$.

\section{Test Microorganisms}

Strains of Samonella enteritidis, Shigella dysenteriae, Staphylococcus aureus, Escherichia coli, and Vibro chorelae; were obtained from Veterinary Research Institute, Vom, nd Plateau State. All the strains were subjected to Gram staining and biochemical tests, for proper identification.

\section{Phytochemical Screening}

Presence of bioactive compounds or secondary metabolites like free anthraquinones, anthraquinones glycosides, saponins, tannins, alkaloids, flavonoids and cardiac glycosides were determined using recommended procedures as described by Trease and Evans (2009).

\section{Determination of Antimicrobial Activity}

The antibacterial assay procedures as described by Cheesbrough (2009) and Okeke etal; (2001) were slightly modified and used. Mueller Hinton agar was used as growth medium for the bacterial species. The medium was autoclaved and sterilized at $121{ }^{\circ} \mathrm{C}$ for 15 minutes at $15 \mathrm{lb}$ pressure, and poured into sterile Petri dishes, and allowed to cool to $45{ }^{\circ} \mathrm{C}$ and solidify. The sterilized medium was seeded with $0.1 \mathrm{~mL}$ of pure cultures of test organisms. Each extract (0.4 g) was dissolved in $2.0 \mathrm{~mL}$ of sterile distilled water to make up an initial concentration of $200 \mathrm{mg} / \mathrm{mL}$. A sterile cork borer was used to make holes $6 \mathrm{~mm}$ in diameter and $2 \mathrm{~mm}$ deep and evenly distributed in the inoculated plates. Each hole was filled with $0.1 \mathrm{~mL}$ of extract solution. $200 \mathrm{mg} / \mathrm{mL}$ of ofloxacin solution was used as positive control while sterilised water served as negative control. The inhibition zones diameter of different extracts was observed after $24 \mathrm{~h}$ of incubation at $37^{\circ} \mathrm{C}$.

Ethyl acetate extract showed the highest activity, it was further purified / separated and fractions collected subjected to spectroscopic analysis by the NMR.

\section{Fractionation of Crude Extract.}

Crude ethtyl acetate extract ( $5 \mathrm{~g}$ ) was pre adsorbed on Celite and ground to a fine powder on drying. The fine powder was subjected to Liquid Vacuum Chromatography (LVC) according to the methods described by Hostettmann et al. (1998). The column was run thus: Silica gel GOG (35 g) was introduced under suction into a sintered glass funnel, mounted on a separatory funnel and connected to a vacuum pump. The silica gel $(5 \mathrm{~cm})$ was compacted and tested with n-hexane to check column bleed. The pre adsorbed extract was introduced as a thin layer $(0.6 \mathrm{~cm})$ atop the silica gel layer. The column was run gradient using n- 
hexane and increasing aliquots of ethyl acetate until $100 \%$ ethyl acetate before finally washing with methanol.

Fifty five fractions of $(20 \mathrm{~mL})$ each was collected in sterile bottles labeled (G1-- G55). These fractions were again subjected to antimicrobial assay using Kirby- Bauer method of antibacterial screening. The antibacterial assays yielded three fractions (G22, G34, \&G48). In order to arrive at the fraction with the highest antibacterial activity, the procedure was repeated on the three fractions and they were further separated using thin layer chromatography (TLC). Fraction (G34), with the highest antibacterial activity and showing a single Spot on TLC $\left(\mathrm{R}_{\mathrm{f}} 0.5\right.$; $1: 1, \mathrm{~N}$-hexane/ethyl acetate) was selected for NMR spectroscopic analysis.

\section{Results.}

NMR (Nuclear magnetic resounance) Analysis

NMR spectral analysis was carried out at University of Strathchyde Glasgow, using JEOL$400 \mathrm{MHz}$ Spectrophotometers and these include proton-proton correlation spectroscopy $\left({ }^{1} \mathrm{H}-{ }^{1} \mathrm{H}\right.$ cosy), and Proton - carbon $\left({ }^{1} \mathrm{H}-{ }^{13} \mathrm{C}\right)$, Hetero nuclear multiple bond connectivity (HMBC).The experiments were carried out using $0.01 \mathrm{mg}$ of fraction (G34). The fraction was dissolved in 0.5 $\mathrm{mL}$ of $\mathrm{CDCl}_{3}$. This solution was put into a long thin glass tube and placed within a powerful magnetic field. The sample solution was irradiated with a short pulse of radio frequency. The energy given out was detected using radio receiver detector amplifier. Results were displayed in form of intensity (that is number of absorption) against frequency, and characteristic spectral data was generated.

Table 1: Antibacterial activity of the stem bark extracts of Detarium microcapum

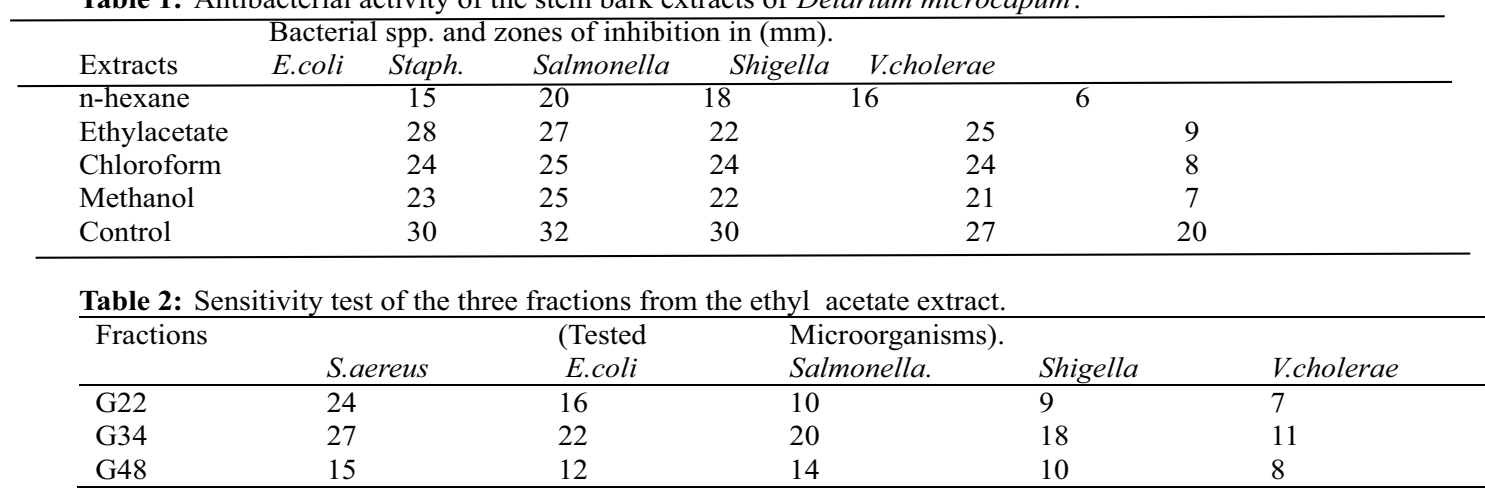

Table 3: Thin layer Chromatography of Fractions G 34, G22 and G48, in (1:1 n-hexane /ethyl- acetate).

\begin{tabular}{lcccl}
\hline Extracts & number of spots & distance moved in $(\mathrm{cm})$ & solvent front $(\mathrm{cm})$ & $\mathrm{R}_{\mathrm{f}}$ value \\
Fraction 22 & 2 & $2.8,4.2$ & 6.5 & $0.43,0.65$ \\
Fraction 34 & 1 & 3.3 & 6.5 & 0.5 \\
Fraction 48 & 2 & $3.5,2.7$ & 6.5 & $0.41,0.4$ \\
\hline
\end{tabular}

Table 4: Proton and $\left({ }^{13} \mathrm{C}-\mathrm{NMR}\right)$ Spectrum data for the separated fraction. NMR spectrum $\left(\mathrm{H}\right.$ and $\left.{ }^{13} \mathrm{C}\right)$ data of fraction $\mathrm{G} 34$ in $\mathrm{CDCl}_{3}$

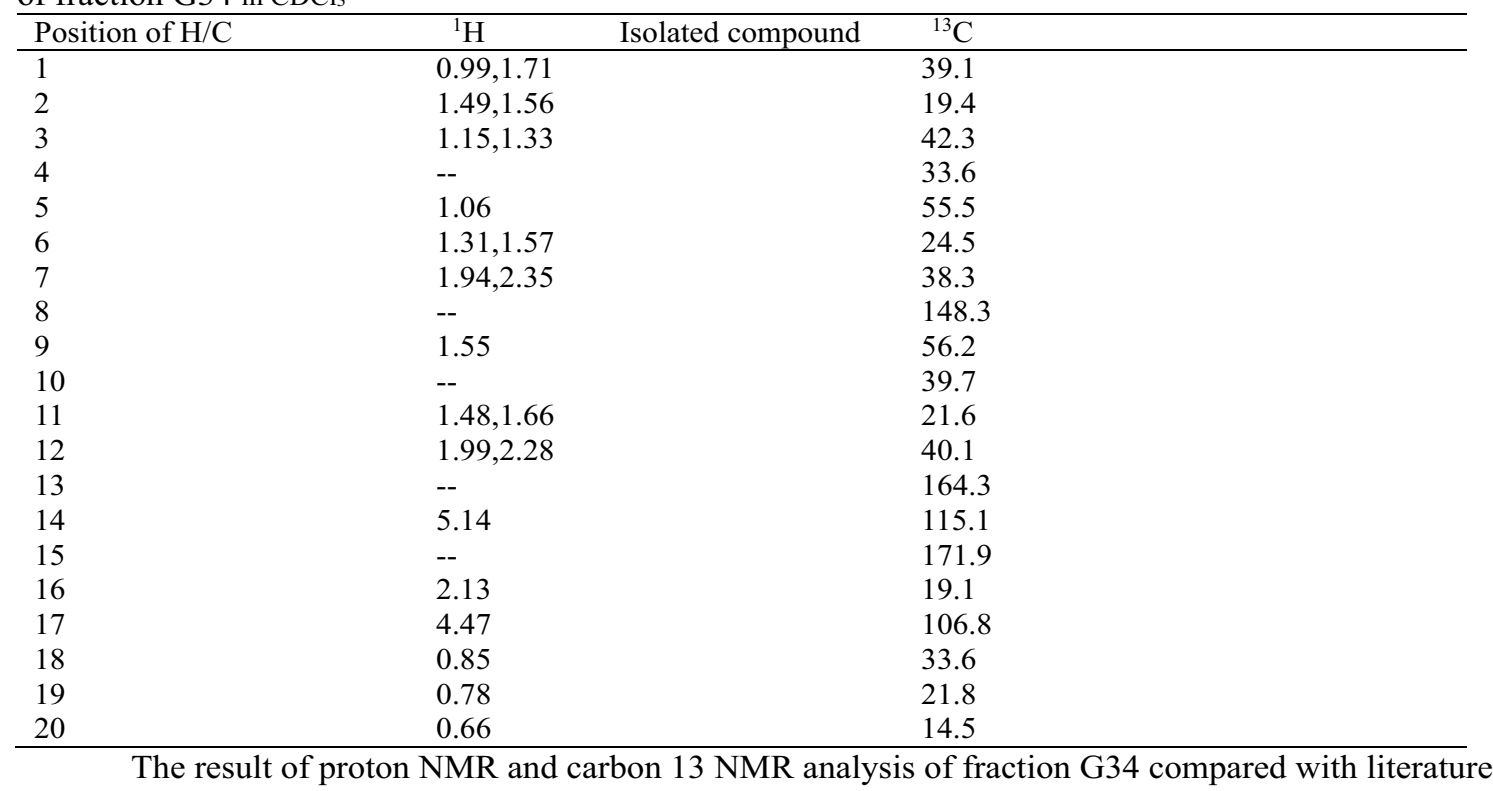
report was as shown in Table 5. 
Table 5: NMR spectral data of fraction $\mathrm{G} 34$ in $\mathrm{CDcl}_{3}$ compared with literature reports.

\begin{tabular}{|c|c|c|c|c|}
\hline Position of ${ }^{1} \mathrm{H} /{ }^{13} \mathrm{C}$ & $(\mathbf{K})$ & ${ }^{13} \mathrm{C}$ & (M) & ${ }^{13} \mathrm{C}$ \\
\hline 1 & $0.99,1.71$ & 39.1 & $1.0,1.73$ & 39.1 \\
\hline 2 & $1.49,1.56$ & 19.4 & $1.5,1.57$ & 19.4 \\
\hline 3 & $1.15,1.33$ & 42.3 & $1.17,1.39$ & 42.1 \\
\hline 4 & -- & 33.6 & -- & 33.6 \\
\hline 5 & 1.06 & 55.5 & 1.08 & 55.5 \\
\hline 6 & $1.31,1.57$ & 24.5 & $1.30,1.55$ & 24.5 \\
\hline 7 & $1.94,2.35$ & 38.3 & $1.98,2.38$ & 38.3 \\
\hline 8 & -- & 148.3 & -- & 148.3 \\
\hline 9 & 1.55 & 56.2 & 1.57 & 56.2 \\
\hline 10 & -- & 39.7 & -- & 39.7 \\
\hline 11 & $1.48,1.66$ & 21.6 & $1.50,1.67$ & 21.5 \\
\hline 12 & $1.99,2.28$ & 40.1 & $1.98,2.31$ & 40.1 \\
\hline 13 & -- & 164.3 & -- & 164.3 \\
\hline 14 & 5.14 & 115.1 & 5.67 & 114.6 \\
\hline 15 & -- & 171.9 & -- & 171.8 \\
\hline 16 & 2.13 & 19.1 & 2.16 & 19.2 \\
\hline 17 & 4.47 & 106. & $4.49,4.55$ & 106.4 \\
\hline 18 & 0.85 & 33.6 & 0.80 & 33.6 \\
\hline 19 & 0.78 & 21.8 & 0.80 & 21.7 \\
\hline 20 & 0.66 & 14.5 & 0.68 & 14.5 \\
\hline
\end{tabular}

Key: $\mathrm{K}=$ Isolated compound; $\mathrm{M}=$ literature reports, (Cavin, et al;2006).

The bioactivity of the isolated compound against test bacteria showed a considerable antibacterial activity with zones of inhibition wider than the crude extract. S.aureus, was most susceptible with the widest zone of inhibition followed by Shigella. The isolated compound showed competitive inhibition with the control (ofloxacin) at $200 \mathrm{mg} / \mathrm{mL}$ (Table 6). The HMBC correlations showing the proton - Carbon relations over long range is shown in Table 7

Table 6: Sensitivity test of Isolated Compound.

\begin{tabular}{lccc}
\hline Microorganisms & Zonesofinhibition (mm) & Fraction (G34) \\
& Control (Ofloxacin) & & \\
\hline E.coli & 29 & 30 & \\
S. aureus. & 31 & 31 & \\
Salmonella & 28 & 29 & \\
Shigella & 30 & 31 & \\
V.cholerae & 11 & 21 & \\
\hline
\end{tabular}

Table.7: HMBC Correlations of the Isolated Compound.

\begin{tabular}{ll}
\hline \multicolumn{1}{c}{ Proton ${ }^{1} \mathbf{H}$} & Carbon13 $\left({ }^{\mathbf{1 3}} \mathbf{C}\right)$ \\
\hline $\mathbf{4 . 8 2}(\mathbf{H}-17 \mathbf{b})$ & $38.3(\mathrm{C}-7), 56.2(\mathrm{C}-9)$ \\
$\mathbf{4 . 4 6}(\mathbf{H}-17 \mathbf{a})$ & $38.3(\mathrm{C}-7), 56.2(\mathrm{C}-9)$ \\
$\mathbf{0 . 6 6}(\mathbf{H}-20)$ & $56.2(\mathrm{C}-9), 55.6(\mathrm{C}-5), 39(\mathrm{C}-10), 40(\mathrm{C}-10)$ \\
$\mathbf{0 . 7 8}(\mathbf{H}-19)$ & $55.6(\mathrm{C}-5), 42.1(\mathrm{C}-3), 34.29(\mathrm{C}-4)$ \\
$\mathbf{0 . 8 5}(\mathbf{H}-18)$ & $55.6(\mathrm{C}-5), 42.2(\mathrm{C}-3), 34.25(\mathrm{C}-4), 22.8(\mathrm{C}-19)$ \\
$\mathbf{2 . 1 4}(\mathbf{H}-16)$ & $164.8(\mathrm{C}-13), 114.8(\mathrm{C}-14), 40(\mathrm{C}-12), 34.1(\mathrm{C}-18)$ \\
$\mathbf{5 . 1 4}(\mathbf{H}-14 \mathbf{b})$ & $19.1(\mathrm{C}-18), 40.1(\mathrm{C}-12), 172(\mathrm{C}-15)$ \\
\hline
\end{tabular}

\section{Discussion.}

The result of the NMR analysis of Fraction (G34), is as in Table 4. A preliminary examination of the ${ }^{1} \mathrm{H}$ and ${ }^{13} \mathrm{C}$ NMR spectrum of fraction $\mathrm{G} 34$ suggest that the compound could be a diterpene. The carbon spectra showed that fraction G34 is a twenty carbon atom compound, made up of one carboxylic, four olefinic, four methyl carbons, others are, seven methylene, two methane, and two quaternary carbons. Further assessment by 2-D NMR showed that in proton-proton correlation spectrocopy $\left({ }^{1} \mathrm{H}-{ }^{1} \mathrm{H} \mathrm{COSY}\right)$, the absence of a long range ${ }^{1} \mathrm{H}-{ }^{1} \mathrm{H}$ correlation between $\mathrm{H}-14$ (5.64) and H-16 (2.13) suggest that the double bond is in the E configuration. A NOE between $\mathrm{H}-$ 20 (0.66) and H-11 (1.66) showed that the methyl group (C-20) has an axial orientation and the side chain is equatorial. In its heteronuclear multiple bond coherence spectrums (HMBC) the long range coupling between $\mathrm{H}-20$ and $\mathrm{C}-19$ methyl protons (0.78) indicates that the methyl group $\mathrm{C} 19$ has an equatorial position, implying that the $\mathrm{C}-18$ methyl group is axial. As H-18 (0.85) showed a NOE with H-15 (1.06), the presence ofa transe - 
decalin ring is evident, since there was no coupling between H-5 and H-20 (Cavin et al., 2006, Urzua et al., 2008).

In summary the correlation between COSY and $\mathrm{HMBC}$ indicates 2 olefinic protons attached to the same carbon atom $(4.47,4.48)$ indicating an oxocyclic double bond typical of a labdane diterpene. Thus the NMR spectral data 1-D $\left({ }^{1} \mathrm{H}\right.$ and ${ }^{13} \mathrm{C}$ ) and 2-D (COSY and HMBC) showed agreement with reported data of a typical diterpene (Cavin, et al., 2006). Fraction G34 was identified as Copalic acid, (chemical formula $\mathrm{C}_{20} \mathrm{H}_{32} \mathrm{O}_{2}$ and molecular weight $304.5 \mathrm{~g} / \mathrm{mol}$.) ' Several authors have reported on the isolation of diterpenes from D. microcarpum. For instance, Lajide et al; (1995) and Cavin et al; (2006) have reported the isolation of diterpenes from the leaves of D. microcarpum.

Among all classes of plant metabolites, diterpenes are considered to be more active and displays a wide spectrum of biological activities, including antibacterial activity (Kuzma et al., 2007). Although, the mechanism(s) responsible for their exceptional biological activity have not yet been very well elucidated, Urzua et al. (2008) have reported that these metabolites promote bacterial lysis and disruption of the cell membrane.

According to these authors, the structural features that promote the efficient antibacterial activity include a lipophilic structure, capable of insertion into the cell membrane, and one strategically positioned hydrogen-bond-donor group (HBD; hydrophilic group), which interacts with the phosphorylated groups on the membrane. These structural features, (the lipophilic structure and the HBD; hydrophilic group) present in copalic acid are the likely ones that promote cell lysis and the disruption of cell membrane.

Copalic acid has been shown to demonstrate considerable antibacterial activity against several oral pathogens that cause periodontal disease. It is an important and selective metabolite that should be considered for the control of periodontitis. This diterpene is also very active against Streptococcus mutans, another key oral pathogen associated with dental caries. These data denote that future oral care products containing this compound could be of great value for application in the treatment and control of oral pathologies.

The fact that the compound is nontoxic (Souza et al., 2011), supports its use in traditional medicine for the management of diarrheal and related infections. The antibacterial sensitivity testing carried out on the isolated compound showed that the compound, has demonstrated high antibacterial activity on the test organisms with zones of inhibition $(30 \mathrm{~mm})$, higher than the crude extracts. The higher activity may be as a result of the presence of the lipolphilic structure and the hydrogen bond donor which unite to cause cell lysis.

It safe to state at this point that the screening and scientific evaluation of plants extracts against microbes may provide new antimicrobial substances. Generally the data generated in this study have provided scientific backing needed for wide use of this plants and the others documented as therapeutic agents for the treatment gastrointestinal infections.

\section{References.}

Aibinu, Ibukun, Peters Folake, Amisu Kehinde, Adesida Solayide, Ojo Mathew, and Tulo Odugbemi (2007): Multi-drug resistance in E. coli 0157 strains and the public Health implication. Journal American Science, 3(3):22-33.

Cavin, A.C; Hay,A.E; Evan H.S; Rossario, S; Drissa, D; Kurt, H; (2006). Bioactive diterpenes from the fruit of Daterium microcarpum. Journal of Natural products, 69:5:769

Cheesbrough, M. (2009).District Laboratory practice in tropical countries 2nd Edition. Cambridge University press pp 157-160.

Hostettmann, K., B. Domon, D. Schaufelberger and M. Hostettmann, (1998). Journal of Chromatography, 283: 137-147.

Lajide I, Eseoubas p., and Mizutani, J; (1995). Termite antifeedant activity in Detarium microcarpum. Phytochemistry, 40 (4): 1101-1104.

Souza, A.B.; Martins, C.H.G.; Souza, M.G.M.; Furtado, N.A.J.C.; Heleno, V.C.G.; Sousa, J.P.B.D.; Rocha, E.M.P.; Bastos, J.K.; Cunha, W.R.; Veneziani.

R. C. S; (2011). Antimicrobial activity of terpenoids from Copaifera langsdorffi against cariogenic bacteria. Human press Jitawa. Pp72-74.

Trease, G.E., and Evans W.C. (2009); Trease and Evans pharmacognosy. 16th ed. Harcourt publishes. Australia. P78

Urzúa, A.; Rezende, M.C; Mascayano, C.; Vasquez, L.A; (2008). Structure-activity study of antibacterial diterpenoids. Molecules, 13, 882-891.

Teklehaymano, A.S., Tilahum, B.J., Giday, F, Mirutse; L.V., (2007). Ethnobotanical study of medicinal plants used by people in Zegie peninsula Ethiopia: Journal of Ethanobiology and Ethanomedicine, 3:1220.

VanWyk, B.E. (2002). A review of ethanobotanical Research in Southern Africa, p78.

World Health organization (2001). Traditional Medicine. Fact sheet number 134. Available on http/www.who.int/media centre fact sheet/fs/134, Nov. 2001). 